\title{
Radiofrequency Thermal Ablation versus Microwave Ablation for Small Hepatocellular Carcinoma
}

\author{
Mohamed Abd El-Hamid Mohamed ${ }^{1}$, Hatem Samir Abd El-Raouf ${ }^{1}$, \\ Waleed Ahmed El Agawy ${ }^{2}$, Mohamed Elsayed Elshewi ${ }^{1}$, \\ Esam Elsaid Hamed ${ }^{2}$ \\ ${ }^{1}$ Hepatology, Gastroenterology and Infectious Diseases Department, Faculty of Medicine, \\ Benha University,Benha,Egypt \\ ${ }^{2}$ Hepatology, Gastroenterology and Infectious Diseases Department, Mahalla Hepatology \\ Teaching Hospital, Egypt.
}

Corresponding Author Esam Elsaid Hamed

Mobile: 01063809608

E mail:

esam.hamed84@gmail .com

Key words: Hepatocellular carcinoma, Radiofrequency ablation, Microwave ablation
Background and Study Aim : Hepatocellular carcinoma (HCC) is the fifth most common form of cancer worldwide and the third most common cause of cancerrelated deaths. This study was designed to investigate the therapeutic efficacy of percutaneous Radiofrequency ablation versus Microwave ablation for small HCC measuring $\leq 3 \mathrm{~cm}$ in diameter.

Patients and methods : This study was carried out in Al-Mahalla Hepatology Teaching Hospital on 30 patients with cirrhosis and small HCC. All the patients were evaluated by thorough history, clinical examination, laboratory investigations, abdominal ultrasound and spiral triphasic CT.

\section{INTRODUCTION}

Hepatocellular carcinoma (HCC) is the fifth most common form of cancer worldwide and the third most common cause of cancer-related deaths. HCC often occurs in the background of a cirrhotic liver [1].

Hepatectomy offers the best outcomes for patients with HCC [2.3]. Unfortunately, there are less than $30 \%$ of cases are amenable to hepatectomy at the time of diagnosis due to advanced tumor stage and underlying liver cirrhosis [4].

When hepatectomy options are contraindicated, image-guided tumor ablation therapy is recommended as the most appropriate therapeutic choice and is considered a potentially curative treatment in properly selected candidates [5].
Results: The mean age was 56.2 \pm 5.8 , $70 \%$ (21) were males and 30\% (9) were females. There was highly statistical significant increase in liver function in MW ablation as regard AST, ALT and bilirubin, and decrease in $\alpha$ FP level of both groups after treatment. There was no significant difference between two groups in the response to treatment as regarding Triphasic CT and complications.

Conclusion: Microwave (MW) and Radiofrequency (RF) ablation are similar in pathologic appearance and imaging characteristics, but RFA has many limitations and many complications. MW ablation offers many of the advantages of RF ablation while overcoming some of its limitations and the heat-sink effect.

In the past two decades, thermal ablation therapy by using energy sources has been increasingly accepted due to the advantages of greater capacity to ablate HCC with fewer treatment sessions. Among the thermal ablation therapy Radiofrequency (RF) ablation and Microwave (MW) ablation are the most commonly used modalities [6.7].

Radiofrequency (RF) ablation has been considered to be the most common thermal ablation modality worldwide for early stage HCC, with $80-95 \%$ complete tumor necrosis and $33-57 \%$ 5-year survival [8].

Microwave (MW) ablation, which generates an electromagnetic field in the tissue and causes rapid and homogeneous rotation of molecules in order to damage the tumor thermally. Microwave ablation (MWA) offers many of the advantages of RF ablation. 
In addition, a larger zone of ablation, faster treatment time, more complete tumor kill And overcome heat sink effect of adjacent blood vessel [9].

Microwave ablation results in significantly larger zones of coagulation than does RF ablation this is due to longer lengths of the coagulated zone, as there is no significant difference between MW and RF ablation for short-axis diameter or maximum diameter [10].

\section{PATIENTS AND METHODS}

Type of the study: Prospective (cohort) study.

\section{Patients :}

We enrolled in the study 30 diagnosed patients with cirrhosis and small hepatocellular carcinoma $\leq 3 \mathrm{~cm}$ at Hepatology Department at Al Mahalla Hepatology Teaching Hospital in the period between May 2014 to March 2015, fulfilling all criteria detailed below.

\section{Inclusion criteria:}

1- Solitary tumour $3 \mathrm{~cm}$ or less in diameter.

2- Patients with Child-Pugh class A or B, not candidate for hepatic resection or no possibility of surgical intervention.

\section{Exclusion criteria :}

1- Tumours larger than $3 \mathrm{~cm}$ in diameter.

2- Hepatic metastasis or abdominal lymph node infiltration.

3- Portal vein thrombosis.

4- Tumours located within $1 \mathrm{~cm}$ of the liver hilum, gall bladder or common bile duct.

5- Tumours in the dome of the liver may be unreachable percuaneously.

6- Platelet count less than $60,000 / \mathrm{ml}$ or prothrombin concentration less than $60 \%$.

7- Patients with Child-Pugh class C.

The patients were randomized into two group: Group 1: included 15 patients treated by RF thermal ablation.

Group 2: included 15 patients treated by MW ablation.

\section{Clinical and Laboratory Assessment:}

All patients were subjected to History taking, Thorough clinical examination General: orientation, jaundice, lower limb oedema or other manifestation suggesting hepatic encephalopathy. Local: hepatomegaly, splenomegaly or ascites. Laboratory investigations: viral markers: anti-HCV antibodies and HBsAg. Complete blood count including ( $\mathrm{Hb} \%, \mathrm{WBC}$ and platelets). Serum creatinine, liver function tests including (ALT, AST, alkaline phosphatase, serum albumin, serum bilirubin and prothrombin concentration. Serum alpha fetoprotein before and one month after ablation. Imaging: Abdominal ultrasound for assessment of : Hepatic focal lesion: site, size and echo pattern. Size of spleen and ascites. Spiral triphasic CT: for enhanced criteria of the hepatic lesion which represents the backbone in the diagnosis of $\mathrm{HCC}$ in cirrhotic patients. Liver biopsy or fine needle aspiration (FNA) cytology (if result of triphasic CT is non conclusive). Patients were evaluated for liver function reservoir according Child-Pugh classification [11].

\section{Percutaneous Ablation Procedures :}

Treatment was performed with the patient under conscious sedation and analgesia induced by the administration of diazepam 10-20 mg (Neuril; Nile) or propofol (Deprivan) intravenously. All ablation procedures were performed under local anesthesia with $1 \%$ lidocaine. Real-time ultrasound was used for the guidance and monitoring of ablation procedures. The aim of the treatment was to completely destroy the tumor with a safety margin of $0.5-1.0 \mathrm{~cm}$ normal liver tissue. At the end of the procedure, needle track can be done to prevent any tumor cell dissemination.

\section{Percutaneous RF ablation.}

In this study we used both RITA Medical System and Boston Scientific :

\section{- RITA Medical System:}

This device relies on direct temperature measurement. Five of the electrodes are hollow and contain thermocouples in their tips to measure the tissue temperature. Probe-tip temperatures, tissue impedance and wattage are displayed on the RF generator and are recorded by dedicated software. Maximum power output of the RF generator, amount of electrode array deployment from the trocar and duration of the effective time of the ablation depend on the desired volume of ablation. The needle is expanded up to 4 $\mathrm{cm}$ to achieve safety margin $(0.5-1.0 \mathrm{~cm})$ [12.13].

\section{- Boston Scientific:}

Another manufacturer (Boston Scientific, Natick, MA) device that relies on electrical measurement of tissue impedance rather than on tissue temperature. The electrode is made by an insulated 14-gauge outer needle that 
houses retractable curved electrodes [14]. The needle used is up to $4 \mathrm{~cm}$ which is expanded in the tumor for ablation. The ablation is performed in two phases (phase I \& phase II).

\section{Percutaneous MW ablation.}

\section{- H.S System:}

This microwave delivery system consisted of a mw generator named AMICA Gen., operating at frequency of $2450 \mathrm{MHz}$ and a power output up to $100 \mathrm{~W}$, and a 14 gauge $(14 \mathrm{~g} \times 150 \mathrm{~mm}$ and $14 \mathrm{~g} \times 200 \mathrm{~mm}$ ) cooled shaft electrode, with real-time us guidance, the needle is percutaneous introduced through the guiding needle into the tumor and the active tip is placed in the deepest part of the tumor to completely eradicate the tumor, for small tumors $(\leq 3 \mathrm{~cm})$, single application MWA was performed, to prevent possible tumor seeding, the needle track is cauterized for 10 seconds when the antenna is withdrawn [15].

\section{Statistical analysis :}

Statistical presentation and analysis of the present study was conducted SPSS V.20. Data was expressed into two phases :

I. Descriptive 1- Mean value (X) and Standard Deviation [SD]: for quantitative data. 2- Frequency and percenatage for qualitative data.

II. Analytic by t-student test and Chi-square test. $\mathrm{P}$ value $>0.05$ was considered statistically non significant $\mathrm{P}$ value $\leq 0.05$ was considered statistically significant. $\mathrm{P}$ value $\leq 0.001$ was considered statistically highly significant.

\section{RESULTS}

Baseline features of studied cases are present in (Tables 1,2).
Study was conducted on 30 patients with mean age $56.2 \pm 5.8,70 \%$ (21) were males and 30\% (9) were females.

In the present study The total bilirubin (TB) levels, the AST and ALT levels were significantly elevated at $48 \mathrm{~h}$ in patients after both RF ablation and MW ablation compared with the baseline levels $(\mathrm{P},<0.001)$. The increase in the AST, ALT and total bilirubin (TB) levels was highly significantly larger in MW ablation group than in RF ablation. There were no significant changes of albumin (ALB) after treatment (Table 3).

There was highly significant decrease in $\alpha$ FP level of both groups after treatment shown in table (4).

There was no significant difference between two groups in the response to treatment as regarding Triphasic CT. (Table 5).

There was no statistical significant difference between MWA and RFA as regarding complications (pain, hematoma, abscess and fever). A lowgrade Fever was observed after treatment in 4 patients in MWA group (26.7\%) and in 2 patients of RFA group (13.3\%), it resolved with antipyretic. Pain in the upper abdomen was observed in 3 patients of MWA group (20\%) and in 5 patients of RF group (33.3\%) during the course of sessions, this patient required the administration of analgesics with prescription of Nimesulide $(0.1 \mathrm{~g} / \mathrm{d})$ for 3-4 days. Hematoma occurred in one patient of MWA group (6.7\%). Abscess occurred in one patient of RF group $(6.7 \%)$, it resolved with repeated aspiration. There were no major complications observed in the studied groups. There were no skin burn and tumor seeding in the study (Table 6).

Table (1): Sex distribution among studied groups ( $\mathrm{n}=30$ )

\begin{tabular}{|c|c|c|c|}
\hline \multicolumn{2}{|c|}{ Males } & \multicolumn{2}{c|}{ Females } \\
\hline No & \% & No & \% \\
\hline 21 & 70 & 9 & 30 \\
\hline
\end{tabular}

Table (2): Age distribution among studied groups ( $\mathrm{n}=30$ )

\begin{tabular}{|c|c|}
\hline Variable & Mean \pm SD \\
\hline Age & $56.2 \pm 5.8$ \\
\hline
\end{tabular}


Table (3): Biochemical profile of both groups (MW\& RFA) before \& one month after the end of treatment

\begin{tabular}{|l|c|c|c|c|c|c|}
\hline \multirow{2}{*}{ Test } & \multicolumn{3}{|c|}{ MW group } & \multicolumn{3}{c|}{ RF group } \\
\cline { 2 - 7 } & $\begin{array}{c}\text { Before } \\
\text { mean } \pm \text { DS }\end{array}$ & $\begin{array}{c}\text { After } \\
\text { mean } \pm \text { DS }\end{array}$ & $\begin{array}{c}\text { P } \\
\text { value }\end{array}$ & $\begin{array}{c}\text { Before } \\
\text { mean } \pm \text { DS }\end{array}$ & $\begin{array}{c}\text { After } \\
\text { mean } \pm \text { DS }\end{array}$ & P value \\
\hline AST & $73.3 \pm 49.9$ & $81.2 \pm 51.7$ & $<0.001$ & $57.6 \pm 44.7$ & $54.2 \pm 44.5$ & .0277 \\
ALT & $67.3 \pm 48$ & $73.7 \pm 48.5$ & $<0.001$ & $52.3 \pm 43.5$ & $52.4 \pm 43.2$ & 0.860 \\
Bilirubin (total) & $1.7 \pm 0.7$ & $1.6 \pm 0.8$ & $<0.001$ & $1.2 \pm 0.4$ & $1.3 \pm 0.4$ & 0.167 \\
Albumin & $3.8 \pm 0.5$ & $3.7 \pm 0.5$ & 0.074 & $3.9 \pm 0.4$ & $3.9 \pm 0.5$ & 0.171 \\
\hline
\end{tabular}

Table (4): $\alpha$ feto protein levels before and one month after treatment in both groups, paired comparison of Both groups (MWA \& RFA group)

\begin{tabular}{|l|c|c|c|}
\hline \multirow{2}{*}{ Group } & $\boldsymbol{\alpha}$ F.P pre & $\boldsymbol{\alpha}$ F.P post & \multirow{2}{*}{ P value } \\
\cline { 2 - 3 } & Mean \pm S D & Mean \pm S D & \\
\hline MW (n.15) & $210 \pm 195.3$ & $63.6 \pm 65.4$ & $<0.001$ \\
RFA (n.15) & $169.5 \pm 177.9$ & $45.5 \pm 55.8$ & $<0.001$ \\
\hline
\end{tabular}

Table (5): Criteria of response after treatment in both groups (RFA \&MWA)

\begin{tabular}{|l|c|c|c|c|c|}
\hline \multirow{2}{*}{ Criteria of response } & \multicolumn{2}{|c|}{$\begin{array}{c}\text { MW group } \\
(\mathbf{n = 1 5})\end{array}$} & \multicolumn{2}{c|}{$\begin{array}{c}\text { RF group } \\
(\mathbf{n = 1 5})\end{array}$} & \multirow{2}{*}{ P value } \\
\cline { 2 - 5 } & No & $\%$ & No & $\%$ & \\
\hline Triphasic CT & & & & & \\
$\quad$ Non enhancing & 14 & 93.3 & 13 & 86.7 & 1.0 \\
Enhancing & 1 & 6.7 & 2 & 13.3 & \\
\hline
\end{tabular}

Table (6): Complications of both Groups (RFA \&MWA)

\begin{tabular}{|l|c|c|c|c|c|}
\hline \multirow{2}{*}{ Complications } & \multicolumn{2}{|c|}{$\begin{array}{c}\text { MW group } \\
(\mathbf{n = 1 5})\end{array}$} & \multicolumn{2}{c|}{$\begin{array}{c}\text { RF group } \\
(\mathbf{n = 1 5})\end{array}$} & \multirow{2}{*}{ P value } \\
\cline { 2 - 5 } & No & $\%$ & No & $\%$ & \\
\hline Pain & 3 & 20 & 5 & 33.3 & 0.28 \\
Hematoma & 1 & 6.7 & 0 & - & 1.0 \\
Abscess & - & - & 1 & 6.7 & 0.37 \\
Fever & 4 & 26.7 & 2 & 13.3 & 1.0 \\
\hline
\end{tabular}

\section{DISCUSSION}

Hepatocellular Carcinoma (HCC) has an increasing incidence worldwide, and it is the leading cause of death in patients with cirrhosis. It is the fifth most common cancer and the third most common cause of cancer-related death [16.17].

Microwaves have higher heating efficiency than RF which renders them unaffected by "heat sink" effect resulting in larger ablation volumes achieved in less time [18].
MW ablation offers many of the advantages of $\mathrm{RF}$ ablation and overcoming some of the limitations as conduction of electricity into tissue, a larger zone of ablation, faster treatment time and more complete tumor kill. MW ablation has a much broader power field than does RF ablation up to $2 \mathrm{~cm}$ [9].

The mean age of the study group was $56.2 \pm 5.8$ years.

The earlier age in Egyptians could be explained by the early age of acquisition of viral hepatitis 
due to the high incidence of $\mathrm{HCV}$ and $\mathrm{HBV}$ in some areas, so although the patients in Egypt are relatively young they may still have had 30-40 years of continuous inflammation and necrosis which might be sufficient to develop cirrhosis and eventual HCC at early ages.

Regarding the sex distribution of the studied patients, nearly all the two groups were males.This was in agreement with Omata et al., study who had four females $(9.3 \%)$ in 43 HCC patients [19] and in agreement with El-Kady et al. who had 8 females $(13.8 \%)$ in a study of 58 patients [20] and Livraghi et al. where out of 158 patients 23 were females [21].

The liver biochemical profile in this study (performed before and one month after the end of sessions) showed slight changes after the RF procedure, this was in agreement with Chen et al. who included 110 patients with HCC in their study on RFA [22] and El-Kady et al. who included 58 patients with HCC in their study on RFA using the multiple array (Le Veen) needles, they found slight transient increase in transaminase levels above the pre-ablation level in $77 \%$ of patients [21]. In MWA group there was highly significant change (significant increase) in the liver function tests namely (AST, ALT, bilirubin) after treatment, this was in agreement with Qian et al. and Yamashiki et al. who studied 19 patients with HCC and observed reversible liver dysfunction with elevation of serum level of transaminases in 12 patients after treatement with MW [23.24].

Complete response was observed in 27 patient (90\%), partial response in 3 patients $(10 \%)$ who were treated with another sessions. The results of this study were in agreement with the results of Zhang et al., in which the complete ablation rate was achieved in $83.4 \%(78 / 93)$ of the treated tumors with RF ablation and $86.7 \%(91 / 105)$ in those treated with MW ablation, with no significant difference between RF and MW ablation [25].

In conclusion, MW and RF ablation are means of thermo ablations which are similar in pathologic appearance and imaging characteristics, but RF has many limitations and many complications as it is effective for small and favorably situated tumors, but local progression rates are substantially higher for large tumors $(\geq 3 \mathrm{~cm})$. MW ablation offers many of the advantages of RF ablation while possibly overcoming some of its limitations. MW ablation may be less affected by the heat- sink effect that is thought to contribute to local recurrence after RF ablation.

\section{ACKNOWLEDGEMENT}

The authors would thank Dr. Mohamed ELsayed Elshewi who helped in conducting this study.

\section{Funding: None.}

Conflicts of interest: The authors declare that there is no conflict of interest.

Ethical approval: Was granted by the Institutional Review Board and informed consent was obtained from each patient prior to inclusion in the study.

\section{REFERENCES}

1. El-Serag HB. Epidemiology of Viral Hepatitis and Hepatocellular Carcinoma. Gastroenterology 2012; 142(6): 1264-1273.

2. Cherqui D, Laurent A, Mocellin N, Tayar C, Luciani A, Decaens $\mathrm{T}$ et al. Liver resection for transplantable hepatocellular carcinoma: longterm survival androle of secondary liver transplantation. Ann Surg 2009; 250: 738-746.

3. Shimada K, Sano T, Sakamoto Y and Kosuge T. A long-term follow-up and management study of hepatocellular carcinoma patients surviving for 10 years or longer after curative hepatectomy. Cancer 2005; 104: 1939-1947.

4. Llovet JM, Burroughs A and Bruix J. Hepatocellular carcinoma. Lancet 2003; 362:1907-1917.

5. Llovet JM and Bruix J. Novel advancements in the management of hepatocellular carcinoma in 2008. J Hepatol 2008 ;48 -1: S20-37.

6. Goldberg SN and Ahmed M. Minimally invasive image-guided therapies for hepatocellular carcinoma. J Clin Gastroenterol 2002; 35: S115-129.

7. Lencioni RA, Allgaier HP, Cioni D Olschewski M, Deibert P, Frings $\mathrm{H}$ et al. Small hepatocellular carcinoma in cirrhosis: randomized comparison of radiofrequency thermal ablation versus percutaneous ethanol injection. Radiology 2003; 228: 235-240.

8. Qian GJ, Wang N, Shen Q, Sheng YH, Zhao JQ, Kuang $M$ et al. Efficacy of microwave versus radiofrequency ablation for treatment of small hepatocellular carcinoma: experimental and clinical studies. Eur Radiol 2012; 22: 1983-1990.

9. Wright A, Sampson L, Warner T, Mahvi D and Lee F. Radiofrequency versus Microwave Ablation in a Hepatic Porcine Model. Radiology 2005; 236: 132-139. 
10. Brace C, Laeseke P, Sampson L, Frey T, van der Weide D, Hinshaw L et al. Microwave Ablation with Multiple Simultaneously Powered Smallgauge Triaxial Antennas: Results from an in Vivo Swine Liver Model. Radiology 2007; 244:151156.

11. Pugh R, Murray-Lyon I, Dawson J, Pietroni MC and Williams R. Transection of the oesophagus for bleeding oesophageal varices. Br. J. Surg. 1973; 60: 646-649.

12. Lencioni R, Cioni D and Crocetti L. Percutaneous ablation of hepatocellular carcinoma: state of the art. Liver Transplantation 2004; 10:S91-97.

13. Lencioni R, Cioni D and Bartolozzi C. Percutaneous radiofrequency thermal ablation of liver malignancies: techniques, indications, imaging findings, and clinical results. Abdominal Imaging 2001; 26:345-360.

14. Rhim H, Goldberg S and Dodd G. Essential techniques for successful radiofrequency thermal ablation of malignant hepatic tumors. Radiographics 2001; 21:S17-S35.

15. Kuang M, Lu M, Xie X, Xu H, Mo L, Liu GJ et al. Liver Cancer: Increased Microwave Delivery to Ablation Zone with Cooled-Shaft Antenna Experimental and Clinical Studies. Radiology 2007; 242:914.

16. Sherman M. Hepatocellular carcinoma: epidemiology, surveillance, and diagnosis. Semin Liver Dis 2010; 30: 3-16.

17. Ferlay J, Shin HR, Bray F, Forman D, Mathers C, Parkin DM et al. Estimates of worldwide burden of cancer in 2008: GLOBOCAN 2008. Int J Cancer 2010; 127: 2893-2917.

18. Shibata T, Iimuro Y, Yamamoto Y, Maetani Y, Ametani F, Itoh K et al. Small hepatocellular carcinoma: comparison of radiofrequency ablation and percutaneous microwave coagulation therapy. Radiology 2002; 223:331-337.
19. Omata M, Dan Y and Daniele B. Clinical features, etiology and survial of hepatocellular carcinoma among different countries. Journal of Gastroenteroalogy and Hepatology 2002 ; 17 : 540-549.

20. El-Kady N M, Esmat G, Mahmoud E H B, Darweesh S K, Samar K, Elagawy W A et al. Hypertonic saline-enhanced radiofrequency versus chemoembolization sequential radiofrequency in the treatment of large hepatocellular carcinoma. European Journal of Gastroenterology and Hepatology 2013; (25) 5: 628-633.

21. Livraghi T, Goldberg SN, Lazzaroni S, Meloni F, Ierace T, Solbiati L et al. Small hepatocellular carcinoma: treatment with radiofrequency ablation versus ethanol injection. Radiology 1999; 210: 655-661.

22. Chen MH, Yang W, Yan K, Zou MW, Solbiati L, Dai $Y$ et al. Large liver tumors: protocol for radiofrequency ablation and its clinical application in 110 patient mathematic model, overlapping mode, and electrode placement process. Radiology 2004; 232: 260-271.

23. Qian GJ, Wang N, Shen Q, Sheng YH, Zhao JQ, Kuang $M$ et al. Efficacy of microwave versus radiofrequency ablation for treatment of small hepatocellular carcinoma: experimental and clinical studies. Radiology 2012; 22: 1983-1990.

24. Yamashiki N, Kato T, Bejarano PA, Berho M, Montalvo B, Shebert RT et al. Histopathological changes after microwave coagulation therapy for patients with hepatocellular carcinoma: review of 15 explanted livers. Am J Gastroenterol 2003; 98 : 2052-2059.

25. Zhang L, Wang N, Shen Q, Cheng W and Qian GJ. Therapeutic Efficacy of Percutaneous Radiofrequency Ablation versus Microwave Ablation for Hepatocellular Carcinoma . Plos One 2013; 10: 76119.

Peer reviewers:Rashed M Hassan; Professor of Tropical Medicine, Faculty of Medicine, Zagazig University, Egypt.Editor: Tarik Zaher; Professor of Tropical Medicine, Faculty of Medicine ,Zagazig University, Egypt. 